This is a post-peer-review, pre-copyedit version of an article published in Journal of Business Ethics. The final authenticated version is available online at: http://dx.doi.org/10.1007/s10551-019-04368-5 
Ingratiating with despotic leaders to gain status: The role of power distance orientation and self-enhancement motive

Dirk De Clercq

Tasneem Fatima

Sadia Jahanzeb

Paper accepted for publication in Journal of Business Ethics 


\title{
Ingratiating with despotic leaders to gain status: The role of power distance orientation and self-enhancement motive
}

\begin{abstract}
This study adds to business ethics research by investigating how employees' exposure to despotic leadership might influence their peer-rated workplace status, along with a mediating role of ingratiatory behavior targeted at supervisors and a moderating role of their power distance orientation and self-enhancement motive. Multisource, three-wave data from employees and their peers in Pakistani organizations reveal that exposure to despotic leaders spurs employees' upward ingratiatory behavior, and this behavior in turn can help them attain higher status in the organization. The mediating role of upward ingratiatory behavior also is more prominent among employees with higher levels of power distance orientation and self-enhancement motive. For business ethics scholars, this study thus pinpoints a potentially dangerous pathway—featuring employees' deliberate efforts to impress self-centered, destructive supervisors — by which despotic leadership can generate beneficial outcomes for employees but not for the organization, as well as how this process varies due to key personal characteristics.
\end{abstract}

Keywords: despotic leadership; ingratiatory behavior; workplace status; power distance orientation; self-enhancement motive; conservation of resources theory 


\section{Introduction}

The presence of negative employee-leader relationships, in which leaders do not care for the well-being of their followers, is a critical point of interest in business ethics scholarship (Capezio et al. 2017; Thoroughgood et al. 2018). Such relationships can significantly harm employees' mental well-being and ability to complete their job tasks (Einarsen et al. 2007; Schilling 2009; Wei and Si 2013; Zhang and Xie 2017). Accordingly, previous research identifies different forms of negative leadership, including abusive supervision (Tepper 2000), tyrannical leadership (Ashforth 1994), leader bullying (Ferris et al. 2007), supervisor undermining (Greenbaum et al. 2015), self-serving leadership (Decoster et al. 2014; Rus et al. 2010), hubristic leadership (Sadler-Smith et al. 2019), and despotic leadership (De Hoogh and Den Hartog 2008).

The latter form arguably is the most self-centered and destructive leadership style among the broader category of negative leadership (Naseer et al. 2016; Schilling 2009). As a key distinction, other forms of negative leadership do not explicitly entail a lack of morals exhibited by leaders toward followers, whereas despotic leadership does (De Hoogh and Den Hartog 2008). That is,

unlike tyrannical leadership, abusive supervision, supervisor undermining, and destructive leadership, where the major focus is on oppressive, humiliating, and antagonistic behaviors toward the subordinates and no reference is made to the integrity and ethical character of the leader, despotic leadership additionally encompasses leader behaviors that reflect egoistic motives designed to manipulate, use, and exploit followers for personal gain (Naseer et al. 2016, p. 16). 
We accordingly define despotic leadership as a highly self-centered leadership style that is morally questionable and focused on the pursuit of personal gains at the expense of follower interests.

The morally corrupt, selfish behaviors exhibited by despotic leaders not only deceive followers but also undermine the well-being and legitimate interests of the organization (De Hoogh and Den Hartog 2008). For example, exploitative leaders might force followers to meet expected job requirements, but despotic leaders also expect excessive obedience for the sole purpose of achieving their own personal goals (De Hoogh and Den Hartog 2008; Schilling 2009). Some leadership styles marked by high authoritarianism, such as abusive supervision or tyranny, even might benefit the organization's ability to meet its strategic objectives (Ashforth 1994; Tepper 2000; cf. Naseer et al. 2016). The consistently harmful effects of despotic leadership on both followers and the organization instead compromise the quality of employees' current organizational functioning and long-term career prospects (Aronson 2001; De Clercq et al. 2018). Therefore, we must determine how employees respond to this "most destructive" leadership style (Naseer et al. 2016) and, particularly, how these responses, even if potentially beneficial for employees, might cause harm to organizational well-being.

With this study, we propose that certain behavioral responses might enable employees to avoid the negative outcomes of exposure to despotic leadership, to the extent that their responses create resource gains and add to their status in the workplace, as rated by their peers. Peer-rated workplace status indicates employees' relative standing, in terms of prestige, respect, and prominence, in the eyes of other organizational members (Djurdevic et al. 2017), as informed by those members' holistic assessments of the perceived value that employees contribute to the employing organization (Pearce 2011; Sumanth and Cable 2011). We propose specifically that 
exposure to despotic leadership can increase employees' workplace status if they exhibit upward ingratiatory behaviors in their effort to mitigate the hardships that result from this destructive leadership style (Gordon 1996; Kumar and Beyerlein 1991; Zhang et al. 2016). We also expect that this process might be invigorated by employees' power distance orientation and selfenhancement motive, two personal characteristics that should make ingratiatory responses to negative leadership more acceptable and attractive, respectively (Guzman and Espejo 2015; Lian et al. 2012). Employees with these characteristics might be particularly likely to counter the threat of negative outcomes imposed by this leadership style for their current and future work by devoting significant energy to upward ingratiatory behaviors (De Hoogh and Den Hartog 2008). Upward ingratiatory behaviors are assertive tactics that employees use to impress organizational leaders and prompt positive assessments, even if the followers' interests are not central among the leaders' concerns (Harris et al. 2007; Liden and Mitchell 1988). Such behaviors might manifest in different ways, such as opinion conformity or a tendency to agree with others; other-enhancement, which involves flattery, verbal compliments, and praise; favor rendering, or performing certain tasks for the target voluntarily; and self-promotion, a selffocused form of ingratiation that emphasizes the person's own positive qualities (Kumar and Beyerlein 1991). These four subdimensions are conceptually interrelated; each speaks to employees' deliberate efforts to evoke favorable evaluations from leaders (Kacmar and Valle 1997; Liden and Mitchell 1988). We accordingly treat upward ingratiatory behavior as an overarching construct, consistent with a construct validation study by Kumar and Beyerlein (1991), empirical studies (e.g., Kacmar and Valle 1997; Watt 1993), and the notion that 
employees engage in ingratiatory tactics or not, irrespective of the specific form they take (Pandey 1981). ${ }^{1}$

In addition to expecting a positive relationship of employees' exposure to despotic leadership with upward ingratiatory behavior, and subsequent workplace status, we theorize that this process might be invigorated by employees' power distance orientation (Auh et al. 2016) and self-enhancement motive (Kim et al. 2016). First, a strong power distance orientation captures employees' acceptance that certain organizational members are endowed with more power and have the right to exercise that power by imposing their opinions and preferences on others who occupy less advantaged positions (Kirkman et al. 2009; Li et al. 2015; Li and Sun 2015). Employees with a strong power distance orientation embrace the presence of hierarchical relationships in organizations and find it acceptable for people at lower levels to defer to others who hold more powerful positions (Farh et al. 2007; Tyler et al. 2000). ${ }^{2}$ Second, a selfenhancement motive reflects “an individual employee's sensitivity to other people's perception of him/her and his/her level of motivation to adapt his/her behavior in order to project a good self-image to others" (Yun et al. 2007, p. 749). Employees with a strong self-enhancement motive have a great desire to improve the image they portray to others (Yun et al. 2007), so they likely find it attractive to engage in ingratiatory activities that put themselves in a positive light. We include these two personal characteristics as moderators in this study because they both motivate employees to consider an ingratiatory response to a negative leadership style such

\footnotetext{
${ }^{1}$ We have no a priori reason to believe that despotic leadership exerts fundamentally different effects on any of the subdimensions of ingratiatory behavior, but we also conduct a post hoc analysis, and report the findings in the "Results" section, that confirms the validity of our approach.

${ }^{2}$ As noted subsequently, the empirical context of this study is the power-distant country of Pakistan. Previous research acknowledges wide variation among individuals within a particular country, in terms of their power distance orientation (Kirkman et al. 2009; Lian et al. 2012). The question of how this personal factor, together with a self-enhancement motive, might trigger upward ingratiatory behavior and subsequent workplace status in response to despotic leadership thus might be particularly relevant for our study context but should be informative in other countries too.
} 
as despotism (Choi et al. 2019; Lian et al. 2012). They also complement each other; employees' power distance orientation is more externally oriented, capturing their views of acceptable power differences in the surrounding environment (Kirkman et al. 2009), whereas a self-enhancement motive is more internally driven, reflecting a sensitivity and desire to be perceived in positive ways by other organizational members (Yun et al. 2007). Taken together, these two factors provide a consistent, comprehensive perspective on how employees' individual characteristics may inform the desirability of ingratiating with despotic leaders, which in turn can add to their own workplace status. The status benefits that employees may obtain in the presence of despotic leadership likely increase when they (1) consider unequal power relations between leaders and followers acceptable and (2) have a strong motivation to create a good impression on others, because these two personal features enhance their efforts to ingratiate with their despotic leaders.

\section{COR theory}

To anchor our theoretical arguments about the effect of despotic leadership on the likelihood that employees engage in upward ingratiatory behavior, and their achievement of subsequent workplace status, as well as the role that their power distance orientation and selfenhancement motive might play in this process, we rely on conservation of resources (COR) theory. This theory increasingly informs research at the nexus of leadership and business ethics (e.g., Braun and Peus 2018; Park et al. 2018). It predicts that employees' work behaviors are informed by their desire to avoid resource losses and achieve resource gains (Hobfoll 1989, 2001). The term resources pertains to "those entities that either are centrally valued in their own right, or act as means to obtain centrally valued ends" (Hobfoll 2002, p. 307). In our study context, key resources are the quality of employees' current and future employment situation, which might be compromised by despotic leaders (De Clercq et al. 2018). 
According to COR theory, the threat of resource loss caused by adverse work circumstances motivates employees to perform work behaviors that can generate resource gains, to compensate for the loss (Hobfoll and Shirom 2000). The work challenges that come with being exposed to a self-centered, morally corrupt leadership style such as despotism generate significant resource losses for employees (De Hoogh and Den Hartog 2008; Naseer et al. 2016), which they may seek to undo by performing resource-gaining ingratiatory activities to appeal to or impress their leaders (Bolino et al. 2014; Gordon 1996; Liden and Mitchell 1988). By allocating personal energy to such activities, employees may mitigate fears that the quality of their current and future organizational functioning will be compromised by despotic leaders. We acknowledge that despotic leadership also could drain employees' energy levels to the extent that they seek to conserve rather than expend discretionary energy (Hou et al. 2018). Moreover, ingratiating efforts with despotic leaders might be risky - compared with the alternative, possibly safer option of remaining silent (Xu et al., 2015)_because such efforts increase employees' direct contact with a malicious leader who already has exhibited a lack of caring for employee well-being. However, we expect that the resource gains (e.g., positive leader evaluations) they anticipate achieving with these behaviors ultimately should diminish this risk consideration and stimulate employees to seek to overcome pertinent resource losses (e.g., impoverished work situation, now and in the future) due to this form of leadership adversity, leading to positive resource spirals in the form of a higher relative standing in the organization, as perceived by other organizational members (Djurdjevic et al. 2017; Hobfoll 2001).

Furthermore, COR theory indicates that employees' personal characteristics invigorate compensatory processes, to the extent that the characteristics generate additional resource gains when employees seek to counter the hardship of resource-depleting leadership with adequate 
behavioral responses (Hobfoll 2001; Hobfoll and Shirom 2000). For this study, we theorize that employees' power distance orientation and self-enhancement motive increase their sense of personal satisfaction when they respond to despotic leadership with ingratiatory activities (Guzman and Espejo 2015; Kwang and Swann 2010). That is, their belief that power differentials in leader-follower relations are instrumental for the effective functioning of organizations, as well as their general desire for self-enhancement and associated motivation to make a positive impression on others, might cause employees to find it particularly rewarding to ingratiate with their supervisors, even those who exhibit despotic tendencies (Choi et al. 2019; Lian et al. 2012). In investigating how employees' power distance orientation and self-enhancement motive trigger the translation of despotic leadership into upward ingratiatory behavior, and subsequent workplace status, we consider two critical contingency factors that stimulate employees' impression management activities in a destructive leadership relationship.

\section{Contributions}

We thus seek to contribute to business ethics research in several ways. First, we identify employees' upward ingratiatory behaviors as an understudied response to their exposure to despotic leadership. Previous research has devoted little attention to how employees respond to the resource-draining leadership style of despotism with deliberate efforts to ingratiate with their supervisors (Aronson 2001; Naseer et al. 2016; Schilling 2009). This gap is problematic, because it prevents a complete understanding of how employees might protect themselves against the hardships of this notably destructive leadership style (Schilling 2009). Consistent with COR theory—and with research that identifies positive connections of leaders' Machiavellianism with followers' ingratiatory behaviors (Capezio et al. 2017) or of abusive supervision with impression management behaviors (Lukacik and Bourdage 2018)—we argue that when employees are 
preoccupied with their work situation, due to their exposure to resource-draining despotic leadership, they seek resource gains, such as positive leader evaluations, by exhibiting more upward ingratiatory behaviors (Hobfoll and Shirom 2000). Predicting these likely responses to despotic leadership adds to previous studies that focus on alternative responses to this leadership style, including reduced optimism (De Hoogh and Den Hartog 2008) and unwillingness to engage in citizenship or creative behaviors (Naseer et al. 2016).

Second, we leverage COR theory to pinpoint an important organizational risk, namely, that the consequences of despotic leadership may be underestimated to the extent that employees exposed to this destructive leadership style actually generate resource gain spirals, in the form of enhanced workplace status, by dedicating effort to upward ingratiatory behaviors (Hobfoll and Shirom 2000). Such exposure may enhance employees' relative standing if it prompts them to allocate personal energy to impression-enhancing activities (Scott et al. 2015). Employees generally seek high levels of workplace status, which can generate beneficial outcomes such as positive performance evaluations (Roberson et al. 2007), higher financial compensation (Castilla 2008), and opportunities for promotion (DiPrete and Soule 1988). Yet workplace status as an outcome of their exposure to despotic leadership, and their associated propensity to undertake upward ingratiatory behaviors, remains largely unexplored - a significant oversight in light of evidence that employees' dedicated efforts to impress supervisors in the presence of workplace adversity can shine a positive light on them (Harris et al. 2007; Liden and Mitchell 1988). In particular, studies have theorized that upward impression management behaviors might enhance employees' standing in the organization (Liden and Mitchell 1988; Turnley and Bolino 2001), but empirical studies mostly focus on the effects of these behaviors on supervisors ' performance evaluations (Bolino et al. 2006) or behavioral responses (Stern and Westphal 2010), not on the 
workplace status obtained among organizational peers. With our approach, we reveal a critical challenge for organizations, in that the victims of despotic leadership and their peers might "forgive" leaders for their despotism, instead of expressing dissatisfaction, if they can obtain personal benefits through upward ingratiatory responses in response to such leadership.

Third, we investigate precisely when the achievement of enhanced workplace status, through upward ingratiatory behaviors, is more likely. Employees' power distance orientation and self-enhancement motive have direct effects on their propensity to seek to impress organizational leaders (Guzman and Espejo 2015; Yun et al. 2007). We add a more indirect role; these two personal factors may function as catalysts that generate personal satisfaction when employees seek to appeal to or impress despotic leaders (Lin et al. 2013). Thus, employees' power distance orientation and self-enhancement motive may invigorate the positive effect of their exposure to resource-draining despotic leadership on whether they undertake upward ingratiatory behaviors, which can enhance their workplace status (Hobfoll and Shirom 2000). By considering these roles, we also extend previous studies of the contingent effects of other individual characteristics, such as self-efficacy (Schaubroeck et al. 2017) or emotional stability (De Hoogh and Den Hartog 2009), in terms of how employees react to resource-draining leadership styles.

Fourth, we respond to calls for more research on destructive leadership styles in nonWestern settings (Gentry et al. 2014; Lok and Crawford 2004; Naseer et al. 2016). The empirical setting for this study is Pakistan, which is marked by high levels of uncertainty avoidance (Hofstede et al. 2010). Although employees in uncertainty avoidant cultures might worry that their ingratiatory behaviors will be considered intrusive by despotic leaders, this aspect should be compensated for, because employees tend to feel highly stressed by uncertainty-inducing, 
adverse work relationships (e.g., with despotic leaders, Naseer et al. 2016), such that they are motivated to undo the associated resource losses by engaging in targeted ingratiation efforts. Moreover, Pakistan features high power distance scores, so authoritarian leadership approaches are not uncommon (Hofstede et al. 2010; Khan et al. 2016), and employees may experience a strong need to find adequate strategies to counter their negative effects. Finally, the argument advanced herein, for a trickle-down effect of upward ingratiatory behavior on peer-rated workplace popularity, might be especially relevant in cultural settings characterized by high levels of collectivism, as Pakistan is (Hofstede et al. 2010). That is, organizational colleagues in these settings might attribute greater value to efforts that other members undertake on their behalf to ingratiate with despotic supervisors, such that they consider these efforts positively and endow their undertakers with enhanced workplace status (Scott and Judge 2009).

In the proposed theoretical framework in Figure 1, employees' exposure to despotic leadership stimulates their engagement in upward ingratiatory behaviors, which spur their workplace status. The effort undertaken to appeal to or impress supervisors explains why despotic leadership might increase employees' workplace status. Their power distance orientation and self-enhancement motive also serve as triggers, such that the conversion of despotic leadership into enhanced workplace status, through upward ingratiation, becomes more likely when employees consider it acceptable for organizations to maintain unequal power relations and when they have a strong motivation to create a positive image among others.

[Insert Figure 1 about here]

\section{Hypotheses}

Mediating role of ingratiatory behavior 
We hypothesize a positive link between employees' exposure to despotic leadership and their upward ingratiatory behavior. Despotic leaders are selfish and focus on their personal interests, without consideration of how their behaviors might affect followers' or organizational well-being (De Hoogh and Den Hartog 2008). This leadership style instills significant stress in employees, because they fear for their short- and long-term prospects in the organization (De Clercq et al. 2018; Naseer et al. 2016). According to COR theory, the allocation of employees' energy to specific work behaviors is informed by their desire to counter the harmful effect of their exposure to resource-draining work conditions (Hobfoll 1989, 2001). When employees encounter adverse relationships with despotic leaders, which threaten their current and future work situations, they should feel motivated to circumvent negative outcomes by developing adequate resource-gaining strategies (Hobfoll 2001; Hobfoll and Shirom 2000; Schaubroeck et al. 2017). In particular, exposure to despotic leadership may spur employees to undertake upward ingratiatory behavior, which can generate resource gains in the form of positive leader evaluations and a demonstration of their ability to handle "difficult" leaders (Harris et al. 2007; Liden and Mitchell 1988). As noted, our prediction of this positive relationship between despotic leadership and upward ingratiatory behavior parallels similar research that reveals enhanced upward ingratiation among female followers exposed to Machiavellian leaders (Capezio et al. 2017) or the strong desire by employees to engage in leader-oriented impression management behavior when they are victims of abusive supervision (Lukacik and Bourdage 2018).

Moreover, the more despotic organizational leaders are, the more useful it may seem for employees to invest time in activities to ingratiate with them, in the hope that these activities might change the leaders' attitudes or make them more caring and inclusive (Aronson 2001; Gordon 1996; Kacmar et al. 2004). When leaders act as despots and exhibit low ethical standards 
toward followers, the employees may grow determined to invest significant energy in ingratiatory behaviors to alter this bad treatment (De Hoogh and Den Hartog 2008). The ultimate goal might be to improve the quality of their work life and enhance their ability to meet longterm career goals (Naseer et al. 2016). For example, if they compliment leaders or emphasize their accomplishments, leaders might reciprocate by treating the employees more respectfully and being more receptive to employees' requests (Watt 1993). Leveraging personal energy into upward ingratiatory behaviors thus might appear highly useful (Hobfoll 1989; Hobfoll and Shirom 2000). But if organizational leaders are not despotic, employees already may feel comfortable with their current work situation and do not need to alter leaders' attitudes (Aronson 2001; Naseer et al. 2016), so the perceived value of a resource-gaining strategy such as upward ingratiation diminishes (Hobfoll and Shirom 2000; Scott et al. 2015).

Hypothesis 1: There is a positive relationship between employees' exposure to despotic leadership and their upward ingratiatory behavior.

We also anticipate a positive relationship between employees' upward ingratiatory behavior and workplace status, as rated by their peers. According to COR theory, the resource gains that come with upward ingratiatory behavior may spur a positive resource spiral, to the extent that employees receive favorable assessments of their organizational roles and contributions for this behavior (Hobfoll 2001). Impression-enhancing activities such as ingratiation tend to generate attributions of competence or likeability (Jones and Pittman 1982; Kacmar et al. 2004), whether through other-focused (e.g., opinion conformity, otherenhancement, favor rendering) or self-focused (e.g., self-promotion) (Kacmar et al. 2004; Kumar and Beyerlein 1991) tactics.

Yet we focus explicitly on the impact of employees' upward ingratiation behavior on their workplace status, as rated by their peers (Lvina et al. 2018). That is, consistent with prior 
research, we predict that colleagues may attribute positive qualities to employees who ingratiate with their leaders, even if these ingratiation efforts are not targeted directly at them (Cullen et al. 2014; Levy et al. 1998). This logic is consistent with previous studies. For example, prior research indicates that the political skills required for ingratiation may generate positive impressions among peers, because the resulting efforts enhance collective well-being (Ferris et al. 2000; Luu 2013). Employees' political behaviors also might enhance team cohesiveness, because the entire team reaps the benefits (Lvina et al. 2018). Moreover, employees' upward ingratiatory behavior may enhance their peer-rated workplace status, by placing them more centrally in the organization's internal network (Floyd and Wooldridge 1997). The increased visibility that arises from this central network position should fuel exchanges between employees and colleagues, so the colleagues become more aware of employees' qualities, and employees enjoy greater workplace status (Cullen et al. 2014; Scott and Judge 2009).

In summary, when employees devote significant energy to ingratiate with their supervisors, they become more noticeable, and peers may accord them higher workplace status. The effects of employees' upward ingratiation behaviors spread and enhance their workplace status, by generating enhanced visibility among peers (Bolino et al. 2006; Higgins et al. 2003), and this mechanism should be especially prominent in cultural contexts characterized by high collectivism, such as Pakistan (Hofstede et al. 2010). Similarly, to the extent that employees engage in leader-targeted ingratiation, favorable reactions by supervisors may create a halo effect that leaves positive impressions among peers too (Fisicaro 1988; Lefkowitz 2000).

Hypothesis 2: There is a positive relationship between employees' upward ingratiatory behaviors and their workplace status.

The combination of the first two hypotheses also suggests a mediating role of upward ingratiatory behavior, such that employees' exposure to despotic leadership enhances their 
workplace status because of their efforts to appeal to or impress their supervisors. Previous studies similarly predict a mediating role of upward ingratiatory behavior on the effects of leader-member exchanges (Geertshuis et al. 2015) and career adaptability (Sibunruang and Tolentiono 2016) on positive work outcomes. To extend this research line, we propose that upward ingratiatory behavior mediates the relationship between exposure to despotic leadership and workplace status. The motivation to compensate for the hardship of resource-draining despotic leadership, with resource-enhancing upward ingratiatory behaviors, is a critical mechanism by which despotic leadership might enhance employees' relative standing in their organization (Hobfoll 2001; Hobfoll and Shirom 2000).

Hypothesis 3: Employees' upward ingratiatory behavior mediates the relationship between their exposure to despotic leadership and their workplace status.

\section{Moderating role of power distance orientation}

According to COR theory, upward ingratiatory behaviors in response to despotic leadership are more likely when personal factors can generate further resource gains from this response (Hobfoll 2001). For example, employees with a strong power distance orientation should feel particularly attracted by the possibility of ingratiating with organizational leaders who possess despotic tendencies. These employees are more likely to accept the presence of strong power differentials in organizations, so they may anticipate significant resource gains, in the form of personal satisfaction, when they are able to impress power-driven leaders who exhibit strong despotic tendencies (Guzman and Espejo 2015; Ryan and Deci 2000). This logic echoes research in the realm of abusive supervision, which indicates that this leadership style "is less likely to be evaluated as unfair by high power distance orientation individuals" and that "for high power distance orientation subordinates, abusive supervisory treatment is more normative and consistent with how relations between superiors and subordinates are perceived" (Lian et al. 
2012, pp. 108 and 109, respectively). Accordingly, these employees should be less reluctant to undertake significant ingratiation efforts with leaders who are self-centered and morally corrupt. Similarly, employees with a strong power distance orientation find the power imbalance across hierarchical levels not only acceptable but desirable ( $\mathrm{Li}$ and Sun 2015), to the extent that they even may believe organizational leaders possess some innate superiority that validates their organizational rank (Kirkman et al. 2009). Accordingly, they likely affirm the value and meaningfulness of deliberate leader-targeted ingratiatory efforts, as a means to receive positive evaluations from despotic leaders who "deserve" their organizational standing (Lian et al. 2012). Employees with a strong power distance orientation thus may experience a sense of deservingness when they ingratiate with despotic leaders (Guzman and Espejo 2015; Hobfoll 2001).

In contrast, employees with a low power distance orientation are less willing to succumb to the preferences and wishes of organizational leaders (Lian et al. 2012), and they may find it less personally fulfilling, let alone exciting, to invest in efforts to impress a leader who is morally corrupt and disrespectful. Their propensity to respond to despotic leadership with upward ingratiation accordingly should be lower. Moreover, employees with a weak power distance orientation tend to reject the idea that powerful positions result solely from the leaders' inherent characteristics (Kirkman et al. 2009), so they might find it demeaning to engage in upward ingratiation efforts. These employees also are more sensitive to their treatment from leaders, which may increase the sense of offense they experience when they feel compelled to respond to despotic leadership with discretionary ingratiation efforts (Auh et al. 2016; Lian et al. 2012). In short, the desire to maintain positive leader evaluations by ingratiating with despotic leaders should be weaker among employees who do not believe in or accept the value of unequal power 
relations in organizations, and the positive relationship between despotic leadership and upward ingratiatory behavior should be weaker in this case (Hobfoll and Shirom 2000).

When combined with the aforementioned mediating role of upward ingratiatory behavior, these arguments also indicate a moderated mediation dynamic (Preacher et al. 2007), such that employees' power distance orientation functions as a contingent factor of the indirect effect of their exposure to despotic leadership on their workplace status, through upward ingratiatory behaviors. For employees who consider the presence of unequal power relations in organizations acceptable, dedicated leader-targeted ingratiation efforts offer important mechanisms to explain why they might enjoy enhanced workplace status in the presence of despotic leadership (Guzman and Espejo 2015).

Hypothesis 4a: The positive relationship between employees' exposure to despotic leadership and their upward ingratiatory behavior is moderated by their power distance orientation, such that this relationship is stronger among employees with a stronger power distance orientation.

Hypothesis 4b: The indirect relationship between employees' exposure to despotic leadership and their workplace status through their upward ingratiatory behavior is moderated by their power distance orientation, such that this indirect relationship is stronger among employees with a stronger power distance orientation.

\section{Moderating role of self-enhanced motive}

We similarly expect that the positive relationship is invigorated by employees' selfenhancement motive, that is, when they have a strong desire to make a positive impression on others (Yun et al. 2007). This desire becomes even more salient when employees find themselves in adverse, resource-draining work conditions that might compromise the image they portray to others (Choi et al. 2019; Kwang and Swann 2010). Accordingly, employees with a strong selfenhancement motive should experience strong resource gains, in the form of personal satisfaction, when they are able to mitigate the negative consequences of their exposure to despotic leadership on their current or future organizational standing (Naseer et al. 2016). A self- 
enhancement motive may catalyze them to exhibit upward ingratiatory responses in the presence of despotic leadership, to increase their chances of positive leader evaluations (Yun et al. 2007).

Conversely, employees with a weak self-enhancement motive may experience exposure to despotic leadership as less threatening to the quality of their current and future work situation (Choi et al. 2019). They are less concerned about their ability to obtain positive leader evaluations when despotic leaders challenge their daily work, so their perceived need to engage in upward ingratiatory behavior to counter the associated resource losses is tempered too (Kwang and Swann 2010). That is, employees with a weak self-enhancement motive should experience a lower desire to avoid any negative consequences that might arise from despotic leadership by engaging in deliberate efforts to ingratiate with their leaders (Yun et al. 2007). Ultimately, these employees experience despotic leadership as less harmful for their career prospects, so they are less likely to react to it with resource-gaining strategies to appeal to or impress supervisors.

Similar to the power distance orientation discussion, these arguments indicate the presence of a moderated mediation effect. The resource gains that employees exposed to despotic leadership seek to attain through their upward ingratiatory behavior (Liden and Mitchell 1988) are particularly important in spurring their workplace status, as assessed by their peers, if those employees have a strong intrinsic motivation to impress others (Yun et al. 2007). Conversely, for employees with a weaker self-enhancement motive, the desire to engage in upward ingratiatory behavior, to counter the depletion of their resource bases through the achievement of resource gains, becomes less important for explaining how their exposure to despotic leadership contributes to their workplace status (Hobfoll 2001).

Hypothesis 5a: The positive relationship between employees' exposure to despotic leadership and their upward ingratiatory behavior is moderated by their self-enhancement motive, such that this relationship is stronger among employees with a stronger selfenhancement motive. 
Hypothesis 5b: The indirect relationship between employees' exposure to despotic leadership and their workplace status through their upward ingratiatory behavior is moderated by their self-enhancement motive, such that this indirect relationship is stronger among employees with a stronger self-enhancement motive.

\section{Research method}

\section{Sample and data collection}

To test the hypotheses, we collected data from employees in three Pakistani-based organizations, one that operates in the telecom sector and two that operate in the courier sector. We applied a three-wave design that contained a time lag of three weeks between rounds. The choice of this time lag is consistent with other studies that examine employees' behavioral reactions to despotic leadership (De Clercq et al. 2018; Naseer et al. 2006) and driven by our goal to reduce reverse causality concerns. Yet the time period was not so long that significant organizational events were likely to occur. The surveys were written in English, the official language of higher education and business in Pakistan. In each round, the surveys were accompanied with a cover letter that explained that this research had received ethical approval and that participants could count on complete confidentiality. In particular, the cover letters

mentioned that no individual identifying information would ever be released, that only aggregate summary data would be made available outside the research team, and that they could withdraw from the study at any time. The surveys also underscored that there were no correct or incorrect responses, it was normal for participants to vary in their responses, and it was important to answer questions as honestly as possible. These specifications help reduce the likelihood of acquiescence and social desirability biases (Spector 2006).

The first survey assessed employees' perceptions of despotic leadership, power distance orientation, and self-enhancement motive; the second survey captured their ingratiatory behavior toward their supervisor. In a third survey, we assessed employees' workplace status according to 
peer ratings. We randomly selected peers who worked in the same department and had worked with the focal employees for at least six months, such that they had sufficient knowledge of colleagues' relative standing in the organization. Each peer rated no more than two employees, to prevent data nesting (Naseer et al. 2016). Including a peer-rated measure of workplace status reduces concerns of common method and social desirability biases. Moreover, our focus on peerrated, not supervisor-rated, workplace status, avoids the concern that supervisors' ratings might be influenced by the quality of the relationships employees have with their leaders.

A total of 450 surveys were distributed to possible participants in the three organizations, identified through random selection from employee lists obtained from the organizations' human resource departments. The number of target respondents varied across the three organizations, informed by suggestions from the organizations' senior management in terms of the number of employees that should be considered for participation. However, the random selection of participants, based on alphabetical ordering, from these recommended samples decreased the risk of biased samples, such that the employees likely were representative of their respective employing organizations. Table 1 summarizes pertinent information about the three organizations and the demographic characteristics of the respondents. Of the 450 originally administered surveys, we received 381 in the first round, 319 in the second round, and 289 surveys from peers in the third round. After omitting surveys with incomplete data, we retained 285 completed survey sets for the statistical analysis, for a response rate of $63 \%$. Of the respondents, $33 \%$ were women. The average organizational tenure of all sampled employees was 5 years.

[Insert Table 1 about here]

\section{Measures}


The measures of the five focal constructs relied on scales validated by previous research. Each scale used 7-point Likert anchors.

Despotic leadership. We assessed employees' exposure to despotic leadership with a well-established, six-item scale developed by De Hoogh and Den Hartog (2008), as also used in prior studies of this leadership style in Pakistan (e.g., De Clercq et al. 2018; Naseer et al. 2016). For example, respondents indicated their agreement with statements such as, "My supervisor has no pity or compassion," "My supervisor seeks revenge when wronged," and "My supervisor expects unquestioning obedience of those who report to him/her" (Cronbach's alpha $=.82)$.

Power distance orientation. We applied an eight-item scale, developed by Earley and Erez (1997), to assess employees' power distance orientation, consistent with previous studies of its role in supervisor-employee relationships (e.g., Graham et al. 2018; Kirkman et al. 2009; Umamaheswara and Mukhopadhyay 2019). Employees rated their agreement with statements such as, "Employees who often question authority keep their managers from being effective," "Once a top-level executive makes a decision, people working for the company should not question it," and "Managers who let their employees participate in decisions, lose power" $($ Cronbach's alpha $=.78)$.

Self-enhancement motive. To measure employees' self-enhancement motive, we used a six-item measure developed by Yun and colleagues (2007) and applied in previous studies of the outcomes of employees' exposure to resource-draining leadership (e.g., Choi et al. 2019;

Seckyoung et al. 2016). For example, employees indicated their agreement with items such as, "I am sensitive to the impression that others have about me," "It is important to me to give a good impression to others," and "I tend to change my behaviors to create a good impression to others" $($ Cronbach's alpha $=.90)$. 
Upward ingratiatory behavior. To measure employees' efforts to appeal to or impress their supervisors, we applied a 24-item scale of ingratiatory behavior, developed and validated by Kumar and Beyerlein (1991), which includes four dimensions (opinion conformity, otherenhancement, favor rendering, and self-presentation). On 7-point anchors that range from "never" to "always," respondents indicated, for example, whether "I express work attitudes that are similar to my supervisor's as a way of letting him/her know that the two of us are alike," "I exaggerate my supervisor's admirable qualities to convey the impression that I think highly of him/her," "I try to do things for my supervisor that show my selfless generosity," and "I try to make sure that my supervisor is aware of my successes." The internal consistency of the 24-item measure was high $($ Cronbach's alpha $=.93)$. We performed a second-order confirmatory factor analysis to confirm that the four dimensions loaded on the self-ingratiatory behavior construct. The paths between the second-order factor and each of the first-order factors were strongly significant $(p<.001)$, and the second-order model generated a good fit (confirmatory fit index $=$ .92 ; Tucker-Lewis index $=.89$; incremental fit index $=.92$; root mean square error of approximation $=.07$ ). Thus, our theoretical approach to treat ingratiatory behavior as an overarching construct is empirically justified for our sample.

Workplace status. Empirical studies of employees' workplace status are relatively rare. We applied a five-item scale by Djurdevic et al. (2017). As mentioned, to limit common method bias concerns, we used peer ratings to measure this variable. Notably, this construct does not capture the status granted to employees by specific peers but rather assesses the status that these peers believe the focal employee has achieved in the organization. For example, peers indicated their agreement with items such as, "This person has a great deal of prestige in our organization," 
"This person possesses a high level of prominence in our organization," and "This person occupies a respected position in our organization" (Cronbach's alpha $=.80)$.

Control variables. The analyses included four control variables: gender $(1=$ female $)$, age ( $1=20-30$ years, $2=31-40$ years, $3=41-50$ years, $4=$ above 50 years $)$, organizational tenure (in years), and whether they operated in the telecom or courier industry (with the latter as the base case for the regression analyses).

\section{Results}

The correlation coefficients and descriptive statistics are in Table 2; the regression results are in Table 3. Models 1-4 predict upward ingratiatory behavior, and Models 5-7 predict workplace status. For each model, all the variance inflation factors were lower than the conservative cut-off value of 5.0 (Studenmund 1992), so multicollinearity was not a concern. The constitutive components of the two-way interaction terms, despotic leadership $\times$ power distance orientation and despotic leadership $\times$ self-enhancement motive, were mean-centered (Aiken and West 1991). The interaction terms were added in separate equations (Models 3 and 4), because their simultaneous inclusion in one model can mask true moderating effects (Covin et al. 2006; De Clercq and Belausteguigoitia 2017; Zahra and Hayton 2008).

[Insert Tables 2 and 3 about here]

With Hypothesis 1, we predicted that employees who face the challenge of resourcedraining despotic leadership compensate for the threatened resource loss by engaging in resource-enhancing efforts to impress supervisors. In support of this prediction, we found a positive relationship between despotic leadership and upward ingratiatory behavior in Model 2 ( $\beta$ $=.199, p<.001)$. In relationships that are beyond the scope of our proposed conceptual framework, the results in Model 2 also showed a direct positive relationship of power distance 
orientation $(\beta=.272, p<.001)$ but, somewhat surprisingly, not of self-enhancement motive $(\beta=$ $.065, n s)$ with upward ingratiatory behavior. The zero-order correlation between selfenhancement motive and upward ingratiatory behavior was positive and significant $(\mathrm{r}=.213, p<$ .01 , Table 3 ), but its explanatory power appeared overpowered by employees' exposure to despotic leadership and power distance orientation. The results also confirmed that discretionary efforts aimed at ingratiating with organizational leaders enhanced employees' relative standing in the organization, as manifest in the positive relationship between their upward ingratiatory behaviors and workplace status in Model $7(\beta=.273, p<.001)$, consistent with Hypothesis 2 .

To determine the presence of mediation, we applied the bootstrapping method suggested by Preacher and Hayes (2004), using the Process macro developed by Hayes (2013). This test generates confidence intervals (CIs) for the indirect effect of despotic leadership on workplace status, thereby avoiding the statistical power problems that might emerge due to asymmetric and other non-normal sampling distributions (Hayes 2009; MacKinnon et al. 2004). With 10,000 random samples and replacement from the full sample (Shrout and Bolger 2002), we found that the CI for the indirect effect of despotic leadership on workplace status through upward ingratiatory behavior did not include $0[.016 ; .100]$, indicating the presence of mediation, in support of Hypothesis 3.

Models 3-4 supported the hypothesized invigorating effects of power distance orientation $(\beta=.127, p<.001)$ and self-enhancement motive $(\beta=.120, p<.001)$ on the relationship between despotic leadership and upward ingratiatory behavior. The likelihood that employees' beliefs about the presence of despotic leadership fueled their upward ingratiatory behavior increased when they exhibited high levels of power distance orientation (Hypothesis 4a) and self-enhancement motive (Hypothesis 5a). We depict these results in Figures 2 and 3, with 
corresponding slope analyses (Aiken and West 1991). The relationship of despotic leadership and upward ingratiatory behavior was significant when power distance orientation $(\beta=.276, p<$ $.001)$ and self-enhancement motive $(\beta=.266, p<.001)$ were high, but the relationship became non-significant at low levels of these moderators $(\beta=.022, n s ; \beta=.026, n s$, respectively), in support of Hypotheses 4a and 5a.

[Insert Figures 2 and 3 about here]

To test the moderated mediation effects predicted in Hypothesis $4 b-5 b$, we again relied on Preacher et al.’s (2007) procedure and Hayes's (2013) Process macro. Similar to the bootstrapping approach used to assess mediation, this procedure generates CIs rather than point estimates for the conditional indirect effects (MacKinnon et al. 2004). ${ }^{3}$ First, for the case of power distance orientation, the bootstrap $95 \%$ CIs for the conditional indirect effect of despotic leadership on workplace status at the 16 th percentile of the moderator contained 0 ([-.041, .046]), but the interval did not contain 0 at the 84 th percentile $([.038, .157])$. Furthermore, the CI of the index of moderated mediation (Hayes 2015) did not include 0 ([.013, .067]). Thus, power distance orientation invigorated the positive indirect relationship between despotic leadership and workplace status, through upward ingratiatory behavior, in support of Hypothesis 5a. Second and similarly, the bootstrap 95\% CI for the conditional indirect effect of despotic leadership on workplace status at the 16th percentile of self-enhancement motive contained $0([-.071, .025])$, but the interval did not contain 0 at the 84 th percentile $([.038, .166[)$. The CI of the index of moderated mediation (Hayes 2015) also did not include 0 ([.012, .061]), in line with Hypothesis

\footnotetext{
${ }^{3}$ Consistent with our theoretical framework, the tested model included the moderating effects of power distance orientation and self-enhancement motive on the relationship between despotic leadership and upward ingratiatory behavior, but not between upward ingratiatory behavior and workplace status. A post hoc test confirmed that power distance orientation and self-enhancement motive did not significantly influence the latter relationship.
} 
5b. Overall, these results confirmed the presence of moderated mediation by both personal characteristics and provided support for the study's overall conceptual framework.

\section{Post hoc analysis}

Our conceptualization of upward ingratiatory behavior as a single construct that constitutes 24 interrelated behaviors is consistent with previous research (Kacmar and Valle 1997; Malodia 2013; Pandey 1981; Watt 1993). Moreover, the second-factor model in which the underlying subdimensions of opinion conformity, other-enhancement, favor rendering (which all reflect other-focused ingratiation), and self-promotion (self-focused ingratiation) loaded on one overarching construct generated a good fit. For comprehensiveness, we also undertook a post hoc analysis of each subdimension though. The results were consistent with those reported in Table 3 , regarding the direct relationship between despotic leadership and upward ingratiatory behavior. That is, there were strong positive relationships between despotic leadership and each subdimension of upward ingratiation, as well as between the four subdimensions and workplace status, except that the relationship between the opinion conformity dimension and workplace status was not significant—possibly because such opinion conformity might be perceived by peers as a passive ingratiation strategy. ${ }^{4}$

Moreover, the invigorating effects of power distance orientation and self-enhancement significantly predict each of the four subdimensions of upward ingratiation. In this regard, an argument could be made that the moderating effect of power distance orientation should be stronger for predicting other-focused ingratiatory behavior, whereas the self-enhancement motive should be more meaningful for predicting self-focused ingratiatory behavior (Kacmar et al.

\footnotetext{
${ }^{4}$ The positive relation of exposure to despotic leadership with all four subdimensions of upward ingratiation contrasts with Kacmar et al.'s (2004) conceptual argument that low quality leader relationships should relate positively to self-focused but not other-focused ingratiatory behaviors. Perhaps in a power distant country such as Pakistan, employees are less likely to be offended by the presence of despotic leadership, so they find it appropriate to go out of their way to appease leaders with various ingratiatory behaviors, irrespective of their specific nature.
} 
2004). Instead, the results of our post hoc analysis indicated that the invigorating effects of both personal characteristics generally were stronger in terms of predicting other-focused, rather than self-focused, behaviors. The interpretation of this result warrants great caution, in light of its post hoc nature, but the invigorating effects of the two personal features for self-focused ingratiation seemingly might be subdued in cultural settings that score low on individualism, such as Pakistan (Hofstede et al. 2010).

\section{Discussion}

This study extends business ethics research by examining the connection between employees' exposure to despotic leadership and their workplace status, with a specific focus on unexplored factors that inform this process. Most research on despotic leadership has focused on employee outcomes such as lower job performance, citizenship behavior, and creativity (Naseer et al. 2016) or reduced optimism about their current and future work situations (De Hoogh and Den Hartog 2008), without addressing how employees might gain enhanced workplace status in the presence of this negative leadership style, as informed by their dedicated efforts and pertinent personal characteristics. Leveraging the premises of COR theory (Hobfoll 1989, 2001), we have proposed that a higher relative standing in the workplace, in the presence of despotic leadership, might result from employees' dedicated impression-enhancing efforts aimed at organizational leaders, and their power distance orientation and self-enhancement motive likely invigorate this process. Our empirical results confirm these theoretical predictions.

First, we reveal that employees exposed to despotic leadership are more likely to respond to this adverse work situation with ingratiatory efforts that seek to appeal to or impress supervisors (Liden and Mitchell 1988; Sibunruang and Tolentino 2016). Despotic organizational leaders are selfish and morally corrupt, and they prioritize their personal interests over those of 
individual followers or the organization (De Hoogh and Den Hartog 2008), so employees might anticipate significant resource losses, in terms of the quality of their current work situation and their ability to achieve future career goals (Hobfoll 2001; Naseer et al. 2016). If they devote significant energy to impressing their leaders though, employees may undo the associated hardships and generate positive outcomes for themselves (Gordon 1996; Kacmar et al. 2004). A contrary view might predict that exposure to this leadership style is so energy-draining that it steers employees away from discretionary ingratiation behaviors (Hou et al. 2018; Quinn et al. 2012). The positive relationship that we find instead indicates the stronger impact of employees' desire to overcome their adverse work situation by seeking resource gains through upward ingratiation, which then increases their relative standing in the organization (Hobfoll and Shirom 2000). The dedicated act of ingratiating with a despotic leader generates resource advantages, in the form of higher levels of workplace status, as rated by their peers (Djurdevic et al. 2017).

Second, the mediating role of upward ingratiatory behavior is moderated by employees' power distance orientation and self-enhancement motive (Kirkman et al. 2009; Yun et al. 2007). As we expected, the extent to which employees engage in such behavior in response to despotic leadership is greater when they believe in the usefulness of unequal power relationships between leaders and followers ( $\mathrm{Li}$ and Sun 2015) and want to maintain a positive image for others (Choi et al. 2019). Consistent with COR theory, expected resource gains, obtained from ingratiatory responses to despotic leadership, can compensate for the resource depletion that comes with such leadership, and this process is exacerbated to the extent that employees' personal characteristics make these responses more attractive (Hobfoll and Shirom 2000). Employees who suffer from despotic leaders but can draw on their power distance orientation and self-enhancement motive may perceive value in reacting with upward ingratiatory activities. They derive strong personal 
satisfaction from their discretionary efforts to impress despotic leaders (Ryan and Deci 2000) because they perceive these efforts as justified, reflecting their high power distance orientation (Kirkman et al. 2009), and worthwhile, due to their high self-enhancement motive (Yun et al. 2007) — and these efforts also add to their peer-rated workplace status. In contrast, employees who reject the idea that large power gaps are acceptable in organizations or who have a weaker desire for self-enhancement find less personal value in dedicating significant efforts to ingratiate themselves with despotic leaders. Instead, they might regard the need to perform such activities as demeaning or unnecessary (Choi et al. 2019; Liang et al. 2012), so upward ingratiation is a less likely response, with negative consequences for their workplace status.

Overall, this study's results add to extant research by revealing how upward ingratiatory behavior functions as an unexplored link between a critical aspect of destructive leadership (i.e., despotism) and enhanced workplace status, as well as how employees' power distance orientation and self-enhancement motive can trigger this process. Explicit investigations of leader-targeted responses to despotic leadership are rare (De Clercq et al. 2018; Naseer et al. 2016), despite widespread acknowledgment that employees seek to avoid the harmful consequences of destructive leadership styles by engaging in appropriate response strategies (Krasikova et al. 2013; Rose et al. 2015; Schilling 2009). We contribute to extant research by specifying the concurrent influences of despotic leadership and two personal characteristics on such behavior. Moreover, by considering these moderating roles, we extend previous applications of COR theory that have focused on the contingent effects of other factors-such as emotional intelligence (Hou et al. 2018), group trust (Wu and Lee 2016), or leader-member exchange (Xu et al. 2015) — on how resource-draining leadership styles might generate other work outcomes, such as reduced innovation and knowledge sharing or enhanced silence. Instead, 
we show that employees' power distance orientation and self-enhancement motive prompt them to leverage the experience of despotic leadership into resource-gaining strategies that positively impress leaders, which ultimately enhance their status in the workplace.

\section{Limitations and future research}

This study has several limitations that suggest research avenues. First, we focused on one, specific form of negative leadership — the most destructive and resource-draining form, involving selfish and morally corrupt behaviors by leaders (Naseer et al. 2006). It would be interesting to investigate how much additional variance in upward ingratiatory behaviors might be explained by despotic leadership after controlling for the presence of other negative leadership styles, such as authoritarian leadership, abusive supervision, or pretty tyranny, or for the absence of positive leadership styles, such as leader-member exchanges and transformational leadership.

Second, we examined upward ingratiatory behavior as an explanatory mechanism for the consequences of despotic leadership, in response to calls for continued investigations of the outcomes of authoritarian leadership styles (Li and Sun 2015; Schaubroeck et al. 2017; Zhang and Xie 2017). Other mediators remain unexplored though, such as controversial, problemfocused voice activities (Liang et al. 2012); the championing of innovative, change-inducing ideas (Howell and Boies 2004); or alternative impression management strategies, including exemplification, supplication, and intimidation (Lukacik and Bourdage 2018).

Third, we did not explicitly measure the mechanisms theorized to link employees' exposure to despotic leadership to their upward ingratiatory behaviors, such as their anticipation of positive leader evaluations or their expectations that they can alter leader behaviors with their ingratiation efforts. The hypothesized relationship between despotic leadership and ingratiatory behavior is based on the well-established COR framework (Hobfoll 1989, 2001) - and the 
positive relationship between upward ingratiatory behavior and workplace status, as found herein, confirms that employees can obtain actual benefits from this behavior-yet continued studies might measure these mechanisms directly. Future research could assess the potency of these explanatory mechanisms by accounting for alternative options too, such as (1) motives to take revenge by ignoring the leader or engaging in displaced aggression, based on a social exchange logic (Choi et al. 2019; Emerson 1981); (2) the reduced optimism that employees may experience in the presence of despotism (De Hoogh and Den Hartog 2008); (3) depleted selfregulatory resources in the form of self-regulation impairment (Deng and Leung 2014); or (4) the risk that upward ingratiation efforts might be ill-received by despotic leaders, especially in uncertainty-avoidant cultures (Hofstede et al. 2010). With respect to the last mechanism, it would be interesting to investigate the links among despotic leadership-ingratiation behaviorworkplace status using different time lags, because pertinent resource gains, in the form of enhanced peer-rated status, might be expected to materialize only in the long-term but remain risky in the short-term, due to how despotic leaders might react immediately to ingratiation efforts by their followers. In this sense, our reliance on time lags of three weeks in this study provide a conservative test of the hypothesized relationships. Still, continued research could complement our survey-based approach with explicit, causal accounts of the hypothesized relationships, obtained with experimental designs that measure the focal variables at selected points in time and assess cross-lagged effects.

Fourth, we call for studies that complement our consideration of power distance orientation and self-enhancement motive by noting other personal factors that might exert moderating influences, such as employees’ psychological capital (Bouckenooghe et al. 2019) or risk propensity (Chow et al. 2012). Certain organizational factors could be contingencies too, 
such as organizational climates marked by a strong rivalry for resources (Luo et al. 2006) or perceptions of organizational justice (Georgalis et al. 2015). Further studies might identify the relative salience of various personal and contextual contingencies for channeling employees' personal energy into upward ingratiatory behaviors in adverse leader relationships.

Fifth, we focus on two specific industry sectors, telecom and courier, which might limit the generalizability of the findings. The results indicated that upward ingratiatory behaviors were more likely in the former industry (Model 1, Table 3), but peer ratings of workplace status were higher in the latter (Model 5, Table 3). These results might be explained by the specific nature of the companies - the telecom company is private, whereas the two courier companies are public or semi-public — so qualitative research could investigate the role of organizational cultural factors in determining how employees react to despotic leadership. Although our conceptual arguments are generic and not connected to any particular industry, it also would be interesting to study possibly pertinent industry factors, such as the extent to which "employee care" is a prevalent concern in the industry (e.g., education, social services) or the competitive rivalry that characterizes the external market. For example, two opposing mechanisms might arise from the presence of intensive market competition. On the one hand, adverse market conditions might increase leaders' stress and hence the extent to which employees suffer from negative leader behaviors; on the other hand, these conditions may leave employees more forgiving of leaders' treatment of them (Fehr and Gelfand 2012), because they want to help the organization through difficult times and thus exhibit less propensity to engage in upward ingratiation. Further research could compare the strength of the connection of despotic leadership with upward ingratiation and subsequent workplace status, as well as the moderating roles of different personal characteristics, across multiple industries. 
Sixth, our reliance on data from one country, Pakistan, might constrain the generalizability of the results, though we posit that the arguments apply to many countries, and only their strength might vary across countries. For example, Pakistan's cultural profile (i.e., high uncertainty avoidance and high power distance) might cause employees to respond particularly strongly to uncertainty-inducing despotic leadership with upward ingratiatory work behaviors; this response may be subdued but still present in less risk-averse or hierarchical countries (Hofstede et al. 2010; Khan et al. 2016). The cultural context for our study probably has the strongest influence on the positive relationship between upward ingratiatory behavior and peer-rated workplace status, because the behavior might appear inappropriate or even lead to envy among peers in individualistic cultures. In these cultures, leader-targeted ingratiatory behaviors even may diminish peer-rated workplace status, to the extent that the peers perceive these behaviors as egoistic or short-sighted, at risk of justifying or encouraging despotic leader tendencies and undermining organizational well-being in the long-term. In collectivistic cultures, in contrast, upward ingratiatory behaviors are more likely to spill over into positive attributions of the employees' organizational standing, as this study shows empirically, because the peers anticipate collective benefits when a particular employee seeks to ingratiate with the common supervisor on behalf of the group (Aguinis et al. 1994; Hofstede et al. 2010). Employees in these cultures embrace group support and seemingly enjoy enhanced workplace status when they undertake efforts to ingratiate with the supervisor. Cross-country comparisons accordingly could offer useful insights into whether and how upward ingratiatory behaviors may enhance workplace status, as rated by peers, contingent on how the country scores on the collectivismindividualism continuum. They also could explicate how positive spillover effects, from 
supervisor to peers, might be superseded by peer envy (Smith and Kim 2007) or perceptions of unfairness in cultures that score high on individualism (Colquitt et al. 2001).

\section{Practical implications}

A key premise of this study is that certain behavioral responses to despotic leadership can be useful for employees themselves, while also acknowledging that these responses may drastically compromise organizational effectiveness, to the extent that they somehow make the harms of this destructive leadership seem irrelevant. In particular, employees might benefit when they respond to despotic leadership with adequate resource-gaining strategies, but the resource depletion that stems from this destructive leadership style still requires organizations to discourage it (Aronson 2001; Naseer et al. 2016; Thoroughgood et al. 2011). Identifying despotic leadership can be difficult though, because employees might be reluctant to report it, for fear that despotic leaders will retaliate with even harsher measures (Schilling 2009). Organizations must be proactive in detecting and discouraging despotic leadership, as well as investigating its possible sources, which may include ineffective recruitment or promotion policies (Barry and Wilkinson 2016; Einarsen et al. 2007). They also could develop specific procedures to help human resource managers identify and counsel leaders who exhibit despotic behaviors, and they should establish effective disciplinary measures if these leaders are not willing to change.

Beyond the general recommendation to discourage despotic leadership, this study offers additional value for organizations that might not be able to eliminate despotic tendencies completely from among their leadership ranks. Employees who have the energy and drive to impress despotic leaders might be able to cope better with the hardships that stem from this resource-draining leadership style, and even might benefit from their upward ingratiatory behaviors, in the form of higher status among their peers. But we note a critical caveat to this 
finding: It should not be taken to suggest that employees should artificially inflate their personal qualities or engage in exaggerated flattery and favor rendering. Even if developing their ingratiation skills can help employees cope with negative leadership styles, including despotism, the risk is that these skills also diminish organizational efforts to eradicate the core problemnamely, that leaders with despotic tendencies even exist within the organization. We therefore clearly highlight the danger involved when employees rely on upward ingratiatory behaviors to minimize the threat of despotic leadership, which is particularly prominent among employees with a strong power distance orientation and self-enhancement motive. These employees may be more open to and less skeptical about undertaking upward ingratiation toward leaders who are disrespectful toward them. It is up to organizational decision makers to sensitize employees and discourage them from remaining silent about leader-related problems or restricting themselves to coping with the problems solely with upward ingratiatory behaviors. Instead, employees should be encouraged to describe their experiences with leader despotism, whether through anonymous communication channels or formally appointed ombudsmen (Harrison et al. 2013). Ultimately, venting their concerns can contribute positively to the quality of their own job functioning, as well as that of their employing organization. 


\section{Compliance with ethical standards}

Conflict of interest: The authors declare that they have no conflict of interest.

Ethical approval: All procedures performed in studies involving human participants were in accordance with the ethical standards of the institutional and/or national research committee and with the 1964 Helsinki declaration and its later amendments or comparable ethical standards. 


\section{References}

Aguinis, H., Nesler, M.S., Hosoda, M., and Tedeschi, J.T. (1994). The use of influence tactics in persuasion. Journal of Social Psychology, 134, 429-438.

Aiken, L. S. and West, S. G. (1991). Multiple regression: Testing and interpreting interactions. Newbury Park, CA: Sage.

Aronson, E. (2001). Integrating leadership styles and ethical perspectives. Canadian Journal of Administrative Sciences, 18, 244-256.

Ashforth, B. (1994). Petty tyranny in organizations. Human Relations, 47, 755-778.

Auh, S., Menguc, B., Spyropoulou, S., and Wang, F. (2016). Service employee burnout and engagement: the moderating role of power distance orientation. Journal of the Academy of Marketing Science, 44, 726-745.

Barry, M., and Wilkinson, A. (2016). Pro-social or pro-management? A critique of the conception of employee voice as a pro-social behaviour within organizational behaviour. British Journal of Industrial Relation, 54, 261-284.

Bolino, M.C., Klotz, A.C., and Daniels, D. (2014). The impact of impression management over time. Journal of Managerial Psychology, 29, 266-284.

Bolino, M.C., Varela, J.A., Bande, B., and Turnley, W.H. (2006). The impact of impression management tactics on supervisor ratings of organizational citizenship behavior. Journal of Organizational Behavior, 27, 281-297.

Bouckenooghe, D., De Clercq, D., and Raja, U. (2019). A person-centered, latent profile analysis of psychological capital. Australian Journal of Management, 44, 91-108.

Braun, S., and Peus, C. (2018). Crossover of work-life balance perceptions: Does authentic leadership matter? Journal of Business Ethics, 149, 875-893.

Capezio, A., Wang, L., Restubog, S.L.D., Garcia, P.R.J.M., and Lu, V.N. (2017). To flatter or to assert? Gendered reactions to Machiavellian leaders. Journal of Business Ethics, 141, 1-11.

Castilla, E.J. (2008). Gender, race, and meritocracy in organizational careers. American Journal of Sociology, 113, 1479-1526.

Choi, W., Kim, S.L., and Yun, S. (2019). A social exchange perspective of abusive supervision and knowledge sharing: Investigating the moderating effects of psychological contract fulfillment and self-enhancement motive. Journal of Business and Psychology, 34, 305-319.

Chow, I.H.S., Ng, I., and Gong, Y.Y. (2012). Risk-taking and relational perspective on turnover intentions. The international Journal of Human Resource Management, 23, 779-792.

Colquitt, J.A., Conlon, D.E., Wesson, M.J., Porter, C.O.L.H., and Ng, K.Y (2001). Justice at the millennium: a meta-analytic review of 25 years of organizational justice research. Journal of Applied Psychology, 86, 425-445.

Covin, J.G., Green, K.M., and Slevin, D.P. (2006). Strategic process effects on the entrepreneurial orientation-sales growth rate relationship. Entrepreneurship Theory \& Practice, 30, 57-81.

Cullen, K.L., Fan, J., and Liu, C. (2014). Employee popularity mediates the relationship between political skill and workplace interpersonal mistreatment. Journal of Management, 40, 17601778.

De Clercq, D., and Belausteguigoitia, I. (2017). Overcoming the dark side of task conflict: Buffering roles of transformational leadership, tenacity, and passion for work. European Management Journal, 35, 78-90. 
De Clercq, D., Haq, I.U., Raja, U., Azeem, M.U., and Mahmud, N. (2018). When is an Islamic work ethic more likely to spur helping behavior? The roles of despotic leadership and gender. Personnel Review, 47, 630-650.

Decoster, S., Stouten, J., Camps, J., and Tripp, T. (2014). The role of employees' OCB and leaders' hindrance stress in the emergence of self-serving leadership. Leadership Quarterly, $25,647-659$.

De Hoogh, A.H.B., and Den Hartog, D.N. (2008). Ethical and despotic leadership, relationships with leader's social responsibility, top management team effectiveness and subordinates' optimism: A multi-method study. The Leadership Quarterly, 19, 297-311.

De Hoogh, A.H.B., and Den Hartog, D.N. (2009). Neuroticism and locus of control as moderators of the relationships of charismatic and autocratic leadership with burnout. Journal of Applied Psychology, 94, 1058-1067.

Deng, H., and Leung, K. (2014). Contingent punishment as a double-edged sword: A dual pathway model from a sense-making perspective. Personnel Psychology, 67, 951-980.

DiPrete, T.A., and Soule, W.T. (1988). Gender and promotion in segmented job ladder systems. American Sociological Review, 53, 26-40.

Djurdjevic, E., Stoverink, A.C., Klotz, A.C., Koopman, J., da Motta Veiga, S.P., and Yam, K.C. (2017). Workplace status: The development and validation of a scale. Journal of Applied Psychology, 102, 1124-1147.

Earley, P. C., and Erez, M. (1997). The transplanted executive: Why you need to understand how workers in other countries see the world differently. New York: Oxford University Press.

Einarsen, S., Aasland, M.S., and Skogstad, A. (2007). Destructive leadership behaviour: A definition and conceptual model. The Leadership Quarterly, 18, 207-216.

Emerson, R. M. (1981). Social exchange theory. In M. Rosenberg \& R.H. Turner (Eds.), Social psychology: Sociological perspectives. New York: Basic Books, Inc.

Farh, J.L., Hackett, R.D., and Liang, J. (2007). Individual-level cultural values as moderators of perceived organizational support-employee outcome relationships in China: Comparing the effects of power distance and traditionality. Academy of Management Journal, 50, 715-729.

Fehr, R., and Gelfand, M. J. (2012). The forgiving organization: A multilevel model of forgiveness at work. Academy of Management Review, 37, 664-688.

Ferris, G.R., Perrewé, P.L., Anthony, W.P., and Gilmore, D.C. (2000). Political skill at work. Organizational Dynamics, 28, 25-37.

Ferris, G.R., Zinko, R., Brouer, R.L., Buckley, M.R., and Harvey, M.G. (2007). Strategic bullying as a supplementary, balanced perspective on destructive leadership. Leadership Quarterly, 18, 195-206.

Fisicaro, S.A. (1988). A reexamination of the relation between halo error and accuracy. Journal of Applied Psychology, 73, 239-244.

Floyd, S.W., and Wooldridge, B. (1997). Middle management's strategic influence and organizational performance. Journal of Management Studies, 34, 465-485.

Geertshuis, S.A., Morrison, R.L., and Cooper-Thomas, H.D. (2015). It's not what you say, it's the way that you say it: The mediating effect of upward influencing communications on the relationship between leader-member exchange and performance ratings. International Journal of Business Communication, 52, 228-245.

Gentry, W.A., Eckert, R.H., Munusamy, V.P., Stawiski, S.A., and Martin, J.L. (2014). The needs of participants in leadership development programs: A qualitative and quantitative crosscountry investigation. Journal of Leadership \& Organizational Studies, 21, 83-101. 
Georgalis, J., Samaratunge, R., Kimberley, N., and Lu, Y. (2015). Change process characteristics and resistance to organisational change: The role of employee perceptions of justice. Australian Journal of Management, 40, 89-113.

Gordon, R.A. (1996). Impact of ingratiation on judgments and evaluations: A meta-analytic investigation. Journal of Personality and Social Psychology, 71, 54-70.

Graham, K.A., Dust, S.B., and Ziegert, J.C. (2018). Supervisor-employee power distance incompatibility, gender similarity, and relationship conflict: A test of interpersonal interaction theory. Journal of Applied Psychology, 103, 334-348.

Greenbaum, R.L., Mawritz, M.B., and Piccolo, R.F. (2015). When leaders fail to "walk the talk": Supervisor undermining and perceptions of leader hypocrisy. Journal of Management, 41, 929-956.

Guzman, F.A., and Espejo, A. (2015). Dispositional and situational differences in motives to engage in citizenship behavior. Journal of Business Research, 68, 208-215.

Harris, K.J., Kacmar, K.M., Zivnuska, S., and Shaw, J.D. (2007). The impact of political skill on impression management effectiveness. Journal of Applied Psychology, 92, 278-285.

Harrison, T.R., Hopeck, P., Desrayaud, M., and Imboden, K. (2013). The relationship between conflict, anticipatory procedural justice, and design with intensions to use ombudsman processes. International Journal of Conflict Management, 24, 56-72.

Hayes, A.F. (2009). Beyond Baron and Kenny: Statistical mediation analysis in the new millennium. Communication Monographs, 76, 408-420.

Hayes, A.F. (2013). Introduction to mediation, moderation, and conditional process analysis: A regression-based approach. Guilford Press, New York.

Hayes, A.F. (2015). An index and test of linear moderated mediation. Multivariate Behavioral Research, 50, 1-22.

Higgins, C., Judge, T., and Ferris, G.R. (2003). Influence tactics and work outcomes: A metaanalysis. Journal of Organizational Behavior, 24, 89-106.

Hobfoll, S.E. (1989). Conservation of resources. A new attempt at conceptualizing stress. American Psychologist, 44, 513-524.

Hobfoll, S.E. (2001). The influence of culture, community, and the nested-self in the stress process: Advancing conservation of resource theory. Applied Psychology: An International Review, 50, 337-369.

Hobfoll, S.E. (2002). Social and psychological resources and adaptation. Review of General Psychology, 6, 307-324.

Hobfoll, S.E., and Shirom, A. (2000). Conservation of resources theory: Applications to stress and management in the workplace. In R.T. Golembiewski (Ed.), Handbook of organization behavior ( $2^{\text {nd }}$ ed., pp. 57-81). New York: Dekker.

Hofstede, G.H., Hofstede, G.J., and Minkov, M. (2010). Cultures and organizations: Software of the mind. Intercultural cooperation and its importance for survival ( $3^{\text {rd }} \mathrm{ed}$.). New York: McGraw-Hill.

Hou, X., Li, W., and Yuan, Q. (2018). Frontline disruptive leadership and new generation employees' innovative behaviour in China: the moderating role of emotional intelligence. Asia Pacific Business Review, 24, 459-471.

Howell, J.M., and Boies, K. (2004). Champions of technological innovation: the influence of contextual knowledge, role orientation, idea generation and idea promotion on champion emergence. Leadership Quarterly, 15, 123-143. 
Jones, E.E., and Pittman, T.S. (1982). Toward a general theory of strategic self presentation. In J. Suls (Ed.), Psychological perspectives on the self (Vol. 1, pp. 231-262). Hillsdale, NJ: Lawrence Erlbaum.

Kacmar, K.M., Carlson, D.S., and Bratton, V.K. (2004). Situational and dispositional factors as antecedents of ingratiatory behaviors in organizational setting. Journal of Vocational Behavior, 65, 309-331.

Kacmar, K.M., and Valle, M. (1997). Dimensionality of the measure of ingratiatory behaviors in organizational settings (MIBOS) scale. Educational and Psychological Measurement, 57, 314-328.

Khan, A.K., Moss, S., Quratulain, S., and Hameed, I. (2016). When and how subordinate performance leads to abusive supervision: A social dominance perspective. Journal of Management, doi: 10.1177/0149206316653930.

Kim, S.L., Lee, S., and Yun, S. (2016). Abusive supervision, knowledge sharing, and individual factors. Journal of Managerial Psychology, 31, 1106-1120.

Kirkman, B.L., Chen, G., Farh, J.-L., Chen, Z.X., and Lowe, K.B. (2009). Individual power distance orientation and follower reactions to transformational leaders: A cross-level, crosscultural examination. Academy of Management Journal, 52, 744-764

Krasikova, D., Green, S.G., and LeBreton, J.M. (2013). Destructive leadership: A theoretical review, integration, and future research agenda. Journal of Management, 39, 1308-1338.

Kumar, K., and Beyerlein, M. (1991). Construction and validation of an instrument for measuring ingratiatory behaviors in organizational settings. Journal of Applied Psychology, 76, 619-627.

Kwang, T., and Swann, W.B. (2010). Do people embrace praise even when they feel unworthy? A review of critical tests of self-enhancement versus self-verification. Personality and Social Psychology Review, 14, 263-280.

Lefkowitz, J. (2000). The role of interpersonal affective regard in supervisory performance: literature review and proposed causal model. Journal of Occupational and Organizational Psychology, 73, 67-85.

Levy, D.A., Collins, B.E., and Nail, P.R. (1998). A new model of interpersonal influence characteristics. Journal of Social Behavior and Personality, 13, 715-735.

Li, S.-L., He, W., Yam, K.C., and Long, L.-R. (2015). When and why empowering leadership increases followers' taking charge: A multilevel examination in China. Asia Pacific Journal of Management, 32, 645-670.

Li, Y., and Sun, J.-M. (2015). Traditional Chinese leadership and employee voice behavior: A cross-level examination. The Leadership Quarterly, 26, 172-189.

Lian, H., Ferns, D.L., and Brown, D.J. (2012). Does power distance exacerbate or mitigate the effects of abusive supervision? It depends on the outcome. Journal of Applied Psychology, 97, 107-123.

Liang, J., Farh, C.I.C., and Farh, J. (2012). Psychological antecedents of promotive and problemfocused voice: A two-wave examination. Academy of Management Journal, 55, 71-92.

Liden, R.C., and Mitchell, T.R. (1988). Ingratiatory behaviors in organizational settings. Academy of Management Review, 13, 572-587.

Lin, W., Wang, L., and Chen, S. (2013). Abusive supervision and employee well-being: The moderating effect of power distance orientation. Applied Psychology: An International Review, 62, 308-329. 
Lok, P., and Crawford, J. (2004). The effect of organisational culture and leadership style on job satisfaction and organisational commitment: A cross-national comparison. Journal of Management Development, 23, 321-338.

Lukacik, E.-R., and Bourdage, J.S. (2018). Exploring the influence of abusive and ethical leadership on supervisor and coworker-targeted impression management. Journal of Business and Psychology, doi:10.1007/s10869-018-9593-2.

Luo, X., Slotegraaf, R.J., and Pan, X. (2006). Cross-functional "coopetition": The simultaneous role of cooperation and competition within firms. Journal of Marketing 70, 67-80.

Luu, T.T. (2013). Corporate social responsibility, upward influence behavior, team processes and competitive intelligence. Team Performance Management, 19, 6-33.

Lvina, E., Johns, G., and Vandenberghe, C. (2018). Team political skill composition as a determinant of team cohesiveness and performance. Journal of Management, 44, 1001-1028.

MacKinnon, D.P., Lockwood, C.M., and Williams, J. (2004). Confidence limits for the indirect effect: Distribution of the product and resampling methods. Multivariate Behavioral Research, 39, 99-128.

Malodia, L. (2013). Influence of employees' ingratiation on organizational citizenship behavior: An empirical study. Business Perspectives and Research, 1, 47-54.

Naseer, S., Raja, U., Syed, F., Donia, M.B.L., and Darr, W. (2016). Perils of being close to a bad leader in a bad environment: Exploring the combined effects of despotic leadership, leader member exchange, and perceived organizational politics on behaviors. The Leadership Quarterly, 27, 14-33.

Pandey, J. (1981). Effects of Machiavellianism and degree of organizational formalization on ingratiation. Psychologia, 24, 41-46.

Park, J.H., Carter, M.Z., DeFrank, R.S., and Deng, Q. (2018). Abusive supervision, psychological distress, and silence: The effects of gender dissimilarity between supervisors and subordinates. Journal of Business Ethics, 153, 775-792.

Pearce, J.L. (2011). Introduction: The power of status. In J. L. Pearce (Ed.), Status in management and organizations (pp. 1-22). Cambridge, UK: University Press.

Preacher, K.J., Rucker, D.D., and Hayes, A.F. (2007). Assessing moderated mediation hypotheses: Theory, methods, and prescriptions. Multivariate Behavioral Research, 42, 185227.

Quinn, R.W., Spreitzer, G.M., and Lam, C.F. (2012). Building a sustainable model of human energy in organizations: Exploring the critical role of resources. Academy of Management Annals, 6, 337-396.

Roberson, L., Galvin, B.M., and Charles, A.C. (2007). When group identities matter: Bias in performance appraisal. In J. P. Walsh \& A. P. Brief (Eds.). Academy of Management Annals (Vol. 1, pp. 617-650). Philadelphia, PA: Erlbaum.

Rose, K., Shuck, B., Twyford, D., and Bergman, M. (2015). Skunked: An integrative review exploring the consequences of the dysfunctional leader and implications for those employees who work for them. Human Resource Development Review, 14, 64-90.

Rus, D., van Knippenberg, D., and Wisse, B. (2010). Leader self-definition and leader selfserving behavior. Leadership Quarterly, 21, 509-529.

Ryan, R.M., and Deci, E.L. (2000). Self-determination theory and the facilitation of intrinsic motivation, social development, and well-being. American Psychologist, 55(1): 68-78.

Sadler-Smith, E., Robinson, G., Akstinaite, V., and Wray, T. (2019). Hubristic leadership: Understanding the hazard and mitigating the risks. Organizational Dynamics, 48, 8-18. 
Schaubroeck, J.M., Shen, Y., and Chong, S. (2017). A dual-stage moderated mediation model linking authoritarian leadership to follower outcomes. Journal of Applied Psychology, 102, 203-214.

Schilling, J. (2009). From ineffectiveness to destruction: A qualitative study on the meaning of negative leadership. Leadership, 5, 102-128.

Scott, B.A., and Judge, T.A. (2009). The popularity contest at work: Who wins, why, and what do they receive? Journal of Applied Psychology, 94, 20-33.

Scott, K.L., Tams, S., Schippers, M.C., and Lee, K.Y. (2015). Opening the black box: Why and when workplace exclusion affects social reconnection behaviour, health, and attitudes. European Journal of Work and Organizational Psychology, 24, 239-255.

Seckyoung, L. K., Lee, S., and Yun, S. (2016). Abusive supervision, knowledge sharing, and individual factors. Journal of Managerial Psychology, 31, 1106-1120.

Shrout P.E., and Bolger, N. (2002) Mediation in experimental and nonexperimental studies: New procedures and recommendations. Psychological Methods 7, 422-455.

Sibunruang, H., and Tolentino, L.R. (2016). Ingratiation as an adapting strategy: Its relationship with career adaptability, career sponsorship, and promotability. Journal of Vocational Behavior, 92, 135-144.

Smith, R.H., and Kim, S.H. (2007). Comprehending envy. Psychological Bulletin, 133, 46-64.

Spector, P.E. (2006). Method variance in organizational research: Truth or urban legend? Organizational Research Methods, 9, 221-232.

Stern, I., and Westphal, J.D. (2010). Stealthy footsteps to the boardroom: Executives' backgrounds, sophisticated interpersonal influence behavior, and board appointments. Administrative Science Quarterly, 55, 278-319.

Studenmund, A.H. (1992). Using econometrics: A practical guide. New York: Harper Collins.

Sumanth, J.J., and Cable, D.M. (2011). Status and organizational entry: How organizational and individual career status affect justice perceptions of hiring systems. Personnel Psychology, 64, 963-1000.

Tepper, B.J. (2000). Consequences of abusive supervision. Academy of Management Journal, 43, $178-190$.

Thoroughgood, C.N., Hunter, S.T., and Sawyer, K.B. (2011). Bad apples, bad barrels, and broken followers? An empirical examination of contextual influences on follower perceptions and reactions to aversive leadership. Journal of Business Ethics, 100, 647-672.

Thoroughgood, C.N., Sawyer, K.B., Padilla, A., and Lunsford, L. (2018). Destructive leadership: A critique of leader-centric perspectives and toward a more holistic definition. Journal of Business Ethics, 151, 627-649.

Turnley, W.H., and Bolino, M.C. (2001). Achieving desired images while avoiding undesired images: Exploring the role of self-monitoring in impression management. Journal of Applied Psychology, 86, 351-360.

Tyler, T.R., Lind, E.A., and Huo, Y.J. (2000). Cultural values and authority relations: The psychology of conflict resolution across cultures. Psychology, Public Policy, and Law, 6, 1138-1163.

Umamaheswara, R. J., and Mukhopadhyay, S. (2019). Understanding the effects of empowering, transformational and ethical leadership on promotive and prohibitive voice. Personnel Review, 48, 707-730.

Watt, J.D. (1993). The impact of the frequency of ingratiation on the performance evaluation of bank personnel. Journal of Psychology; 127, 171-177. 
Wei, F., and Si, S. (2013). Tit for tat? Abusive supervision and counterproductive work behaviors: The moderating effects of locus of control and perceived mobility. Asia Pacific Journal of Management, 30, 281-296.

Wu, W.-L., and Lee, Y.-C. (2016). Do employees share knowledge when encountering abusive supervision? Journal of Managerial Psychology, 31, 154-168.

$\mathrm{Xu}$, A.J., Loi, R., and Lam, L.W. (2015). The bad boss takes it all: How abusive supervision and leader-member exchange interact to influence employee silence. The Leadership Quarterly, 26, 763-774.

Yun, S., Takeuchi, R., and Liu, W. (2007). Employee self-enhancement motives and job performance behaviors: investigating the moderating effects of employee role ambiguity and managerial perceptions of employee commitment. Journal of Applied Psychology, 92, 745756.

Zahra, S., and Hayton, J.C. (2008). The effect of international venturing on firm performance: The moderating influence of absorptive capacity. Journal of Business Venturing, 23, 195220.

Zhang, L., Deng, Y., Zhang, X., and Hu, E. (2016). Why do Chinese employees build supervisor-subordinate guanxi? A motivational analysis. Asia Pacific Journal of Management, 33, 617-648.

Zhang, Y., and Xie, Y.-H. (2017). Authoritarian leadership and extra-role behaviors: A roleperception perspective. Management and Organization Review, 13, 147-166. 
Figure 1: Conceptual model

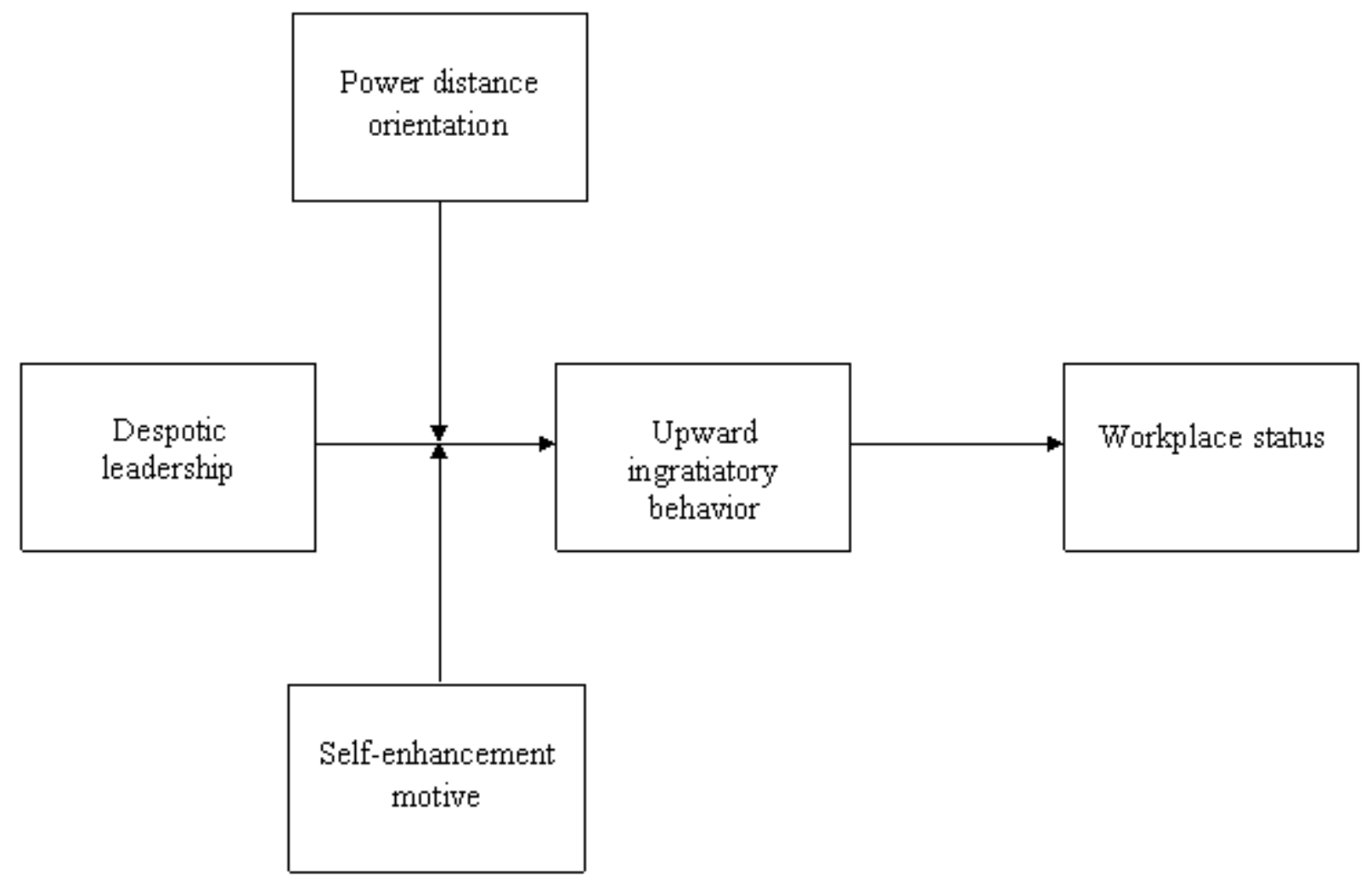


Figure 2: Moderating effect of power distance orientation on the relationship between despotic leadership and upward ingratiatory behavior

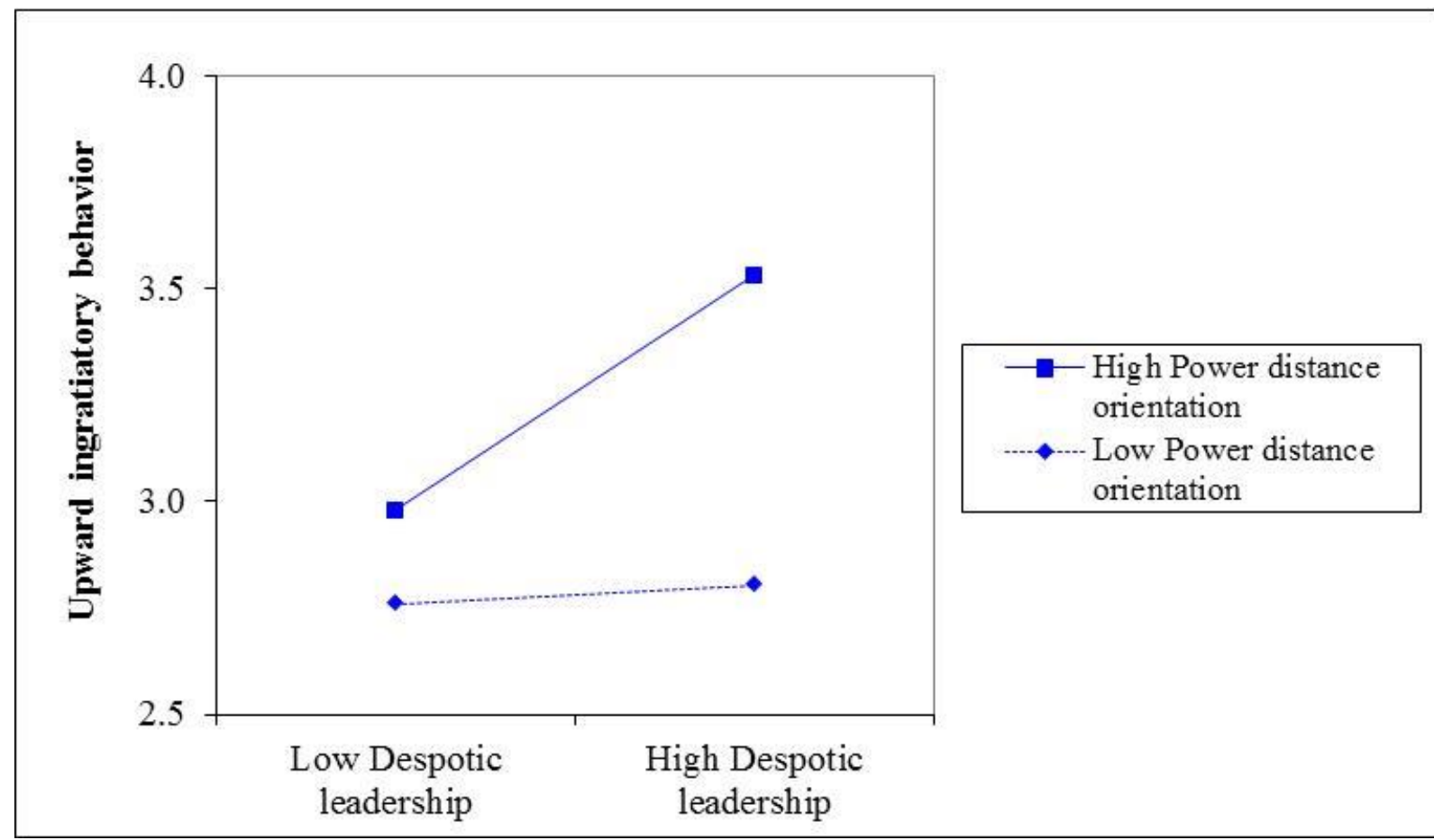

Figure 3: Moderating effect of self-enhancement motive on the relationship between despotic leadership and upward ingratiatory behavior

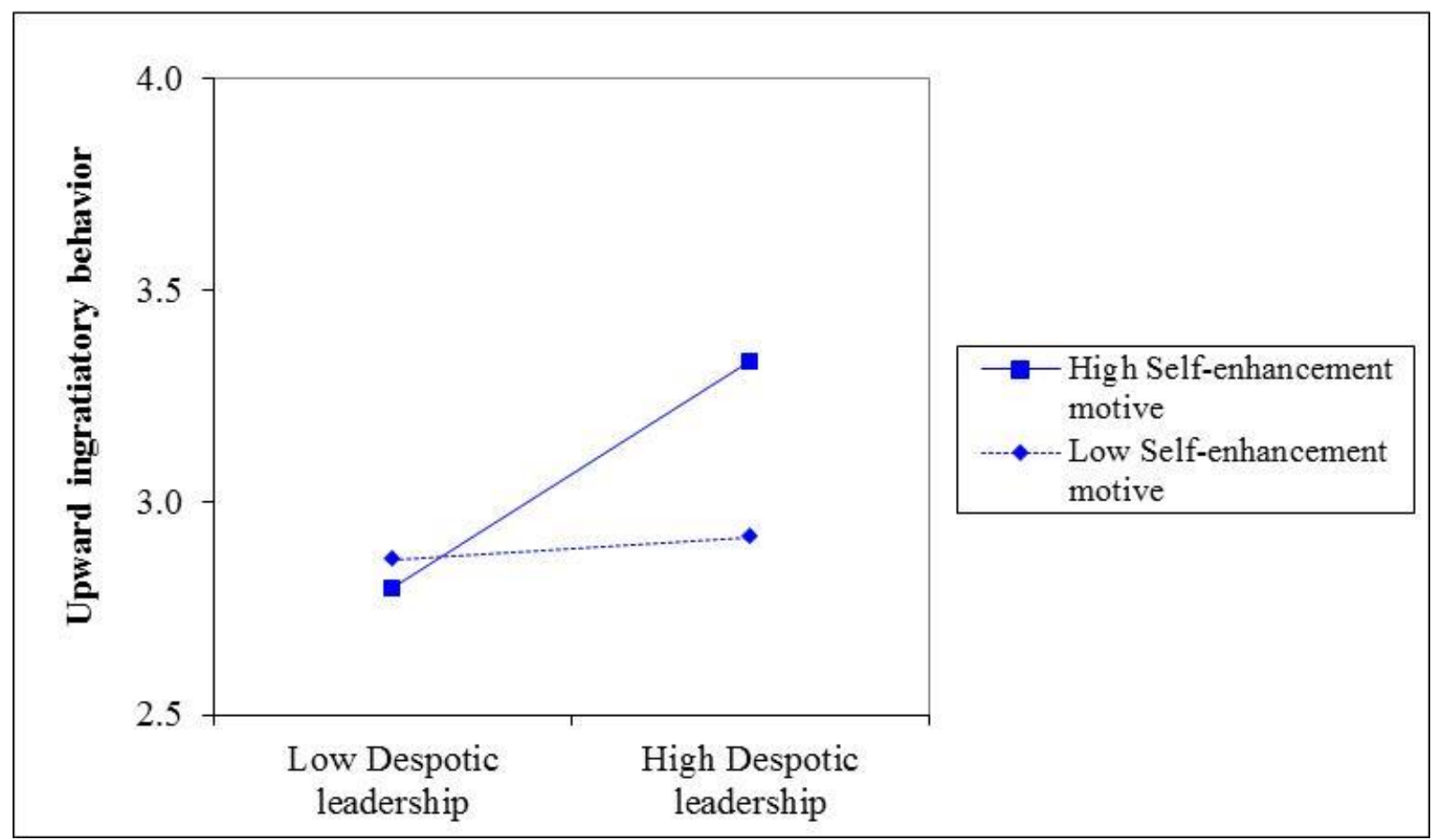


Table 1: Responses and demographic characteristics by organization

\begin{tabular}{|c|c|c|c|}
\hline & Organization 1 & Organization 2 & Organization 3 \\
\hline Industry & Telecom & Courier & Courier \\
\hline Number of employees & 1,200 & 400 & 1,500 \\
\hline Target employees & 130 & 90 & 230 \\
\hline Number of respondents & 81 & 55 & 149 \\
\hline Response rate & $62 \%$ & $61 \%$ & $65 \%$ \\
\hline \multicolumn{4}{|l|}{ Participant characteristics } \\
\hline Gender distribution ( $\%$ female) & $39 \%$ & $27 \%$ & $27 \%$ \\
\hline Age (4-point scale) & 1.60 & 2.36 & 1.86 \\
\hline Organizational tenure (in years) & 3.71 & 9.36 & 5.40 \\
\hline
\end{tabular}


Table 2: Correlation table and descriptive statistics

\begin{tabular}{lccccccccccc}
\hline & Mean & SD & 1 & 2 & 3 & 4 & 5 & 6 & 7 & 8 & 9 \\
\hline 1. Gender & .333 & .472 & -- & & & & & & & \\
2. Age & 1.818 & .806 & -.099 & -- & & & & & & \\
3. Organizational tenure & 5.279 & 5.627 & $-.249^{* *}$ & $.661^{* *}$ & -- & & & & & \\
4. Telecom industry & .523 & .500 & $.124^{*}$ & $-.286^{* *}$ & $-.293^{* *}$ & -- & & & \\
5. Despotic leadership & 3.467 & 1.301 & .083 & $-.126^{*}$ & $-.122^{*}$ & $.132^{*}$ & $(.819)$ & & \\
6. Power distance orientation & 3.922 & 1.115 & -.018 & .054 & .090 & -.058 & $.358^{* *}$ & $(.783)$ & \\
7. Self-enhancement motive & 4.288 & 1.510 & $-.124^{*}$ & .056 & $.205^{* *}$ & $-.139^{*}$ & $.176^{* *}$ & $.504^{* *}$ & $(.899)$ & \\
8. Upward ingratiatory & 3.641 & 1.145 & $.197^{* *}$ & $-.137^{*}$ & $-.119^{*}$ & $.195^{* *}$ & $.379^{* *}$ & $.373^{* *}$ & $.213^{* *}$ & $(.927)$ \\
$\quad$ behavior & & & & & & & & & \\
9. Workplace status & 4.253 & 1.352 & $.204^{* *}$ & $.172^{* *}$ & -.025 & $-.292^{* *}$ & .062 & $.195^{* *}$ & $.118^{*}$ & $.222^{* *}$ & $(.798)$ \\
\hline
\end{tabular}

Notes: $\mathrm{N}=285$. Cronbach's alpha values are shown in parentheses on the diagonal. $* p<.05 ; * * p<.01$.

Table 3: Regression results

\begin{tabular}{|c|c|c|c|c|c|c|c|}
\hline & \multicolumn{4}{|c|}{ Upward ingratiatory behavior } & \multicolumn{3}{|c|}{ Workplace status } \\
\hline & Model 1 & Model 2 & Model 3 & Model 4 & Model 5 & Model 6 & Model 7 \\
\hline Age & -.141 & -.093 & -.119 & -.105 & $.434 * * *$ & $.456 * * *$ & $.482 * * *$ \\
\hline Telecom industry ${ }^{\text {a }}$ & $.355^{*}$ & $.347 * *$ & $.438 * * *$ & $.437 * * *$ & $-.844 * * *$ & $-.818 * * *$ & $-.913 * * *$ \\
\hline Despotic leadership & & $.199 * * *$ & $.149 * *$ & $.146^{* *}$ & & .022 & -.033 \\
\hline Power distance orientation & & $.272 * * *$ & $.237 * * *$ & $.207 * * *$ & & $.184 *$ & .110 \\
\hline Self-enhancement motive & & .065 & .043 & $.087+$ & & .055 & .037 \\
\hline $\begin{array}{l}\text { Despotic leadership } \times \text { self-enhancement } \\
\text { motive }\end{array}$ & & & & $.120 * * *$ & & & \\
\hline Workplace status & & & & & & & $.273 * * *$ \\
\hline $\begin{aligned} & \mathrm{R}^{2} \\
& \Delta \mathrm{R}^{2}\end{aligned}$ & .074 & $\begin{array}{c}.275 \\
.201 * * *\end{array}$ & $\begin{array}{c}.309 \\
.034 * * *\end{array}$ & $\begin{array}{c}.318 \\
.043 * * *\end{array}$ & .184 & $\begin{array}{c}.223 \\
.039 * *\end{array}$ & $\begin{array}{c}.262 \\
.039 * * *\end{array}$ \\
\hline
\end{tabular}

Notes: $\mathrm{N}=285$ (unstandardized regression coefficients). ${ }^{\mathrm{a}}$ Base case $=$ courier industry. ${ }^{+} p<.10 ; * p<.05 ; * * p<.01 ; * * * p<.001$ (two-tailed tests). 